\title{
Education Forum
}

\section{Policy recommendations to enhance nursing education and services among Asean member countries}

\author{
Virya Koy* \\ President of Cambodian Council of Nurses, Chief of Bureau of Nursing and Midwifery, MOH, Cambodia
}

Received: 09 April 2015

Revised: 27 April 2015

Accepted: 24 May 2015

*Correspondence:

Virya Koy,

E-mail: virya2403koy@gmail.com

Copyright: ( $\odot$ the author(s), publisher and licensee Medip Academy. This is an open-access article distributed under the terms of the Creative Commons Attribution Non-Commercial License, which permits unrestricted non-commercial use, distribution, and reproduction in any medium, provided the original work is properly cited.

\begin{abstract}
The initiated the development of an ASEAN Community in 1967, the process will be complete in 2015. An ASEAN community comprises the ASEAN Economic Community (AEC), which has a single market and a production base which is stable, prosperous, highly competitive and with a free flow of goods or services and capitals. All services in ASEAN countries must be prepared for the coming changes. As a leader in the provision of health services of ASEAN countries will benefit most from joining this community. Nursing is an important profession in providing health care services. Therefore nursing schools, which have a major role in producing professional nurses, must prepare nursing staff to be involved in the ASEAN community. They must be able to know related information, for instance the collaborative memorandum of understanding among the ASEAN nursing profession for being the competitively advantaged organization. The exchanging of nursing knowledge and nursing service experience from ten ASEAN countries, establish each other county's viewpoint of this knowledge. Furthermore, from the basis procedure of each country, we can move forward together to strengthen nursing education and nursing service in ASEAN countries and the world.
\end{abstract}

Keywords: ASEAN community, Nursing education, Nursing service, Policy, Recommendation

\section{INTRODUCTION}

Under the ASEAN Economic Community (AEC), a single regional common market of ASEAN countries will be created by 2015 . The regional integration's objective is to create a competitive market of over 600 million people in ASEAN countries: Brunei, Cambodia, Indonesia, Laos, Malaysia, Myanmar, the Philippines, Singapore, Thailand, and Vietnam. There will be free flow of goods, services, investment capital and skilled labor following the liberalization. ${ }^{1}$ These will include tariff reductions and streamlining of certain administrative procedures. Many businesses have begun preparing themselves three years ahead of time to meet the challenges and opportunities of the ASEAN Economic Community (AEC). ${ }^{2,3}$
Health care is one of the sectors to be internationalized. This is definitely a big challenge as it is more complicated than just the popularity of Singapore ${ }^{4}$ and Thailand's ${ }^{5}$ "medical tourism" that patients travel from one country to another seeking better care at lower cost. The legal and licensing frameworks are still needed to be worked out. Therefore, a mutual recognition arrangement has been facilitated to promote the common core competencies among eight sectors and the nursing profession is one of them. With the coming of AEC, nurses need to provide care not only for local people, but also for new groups of clients coming in and out each country from the liberalization. This requires nurses in the ten countries to adjust themselves to the changes. ${ }^{6}$ They need to develop nursing knowledge, nursing system applicable to both local and new clients. In addition, they need to prepare a new generation of nurses who are 
capable for providing nursing care for ASEAN population. $^{7}$

In order to achieve these goals, nurse educators and nurse clinicians of the ten countries need to work closely together as a united group. Mutual Recognition Agreement $^{6}$ would be approved to strengthen professional capabilities by promoting the flow of relevant information and exchange of expertise, experience and best practices suited to the specific needs of ASEAN Member Countries.

MRA provides intended objectives (1) to facilitate mobility of nursing professionals within ASEAN; (2) to exchange information and expertise on standards and qualifications; (3) to promote adoption of best practices on professional nursing services; and (4) provide opportunities for capacity building and training of nurses. To achieve these greatest movement, the sharpening nursing policy is play much more important role to support nurse educators and administrators of each member states to collaborate effectively. Similarly study stated that nursing profession along with allied health care professionals face major changes in response to ongoing National Health System (NHS) service redesign initiatives, pay modernization and the imperative to transform existing models of health and social care. ${ }^{8}$ Addressing these challenges requires an increased nursing contribution and influence in healthcare policy across clinical and educational areas. ${ }^{9}$

Moreover, the International Council of Nurses (ICN) also proposed that nurses could make an important contribution to the development of appropriate and effective health policy. ${ }^{10}$ The ICN strongly promotes and supports efforts to improve the preparation of nurses for policy development. The comings of the ASEAN Economic Community or AEC in 2015 are going to bring more changes to us. The policy of ASEAN community also impact on nursing profession both in nursing education and nursing service, which provides quality of health care for their clients. ${ }^{3}$

The awareness of the impact to the clients, Faculty of Nursing, Chulalongkorn University organized international symposium in order to discuss the enhancement and strengthening nursing education and nursing services. This symposium was invited nurse leaders from respect ASEAN member countries to share to the main objectives:

1. To develop the network and collaboration between nursing education and nursing service in ASEAN among education, practice and research;

2. To exchange knowledge of nursing education and nursing service in ASEAN for promoting healthy people under cultural context of ASEAN Community;

3. To develop guideline of nursing education and nursing service among ASEAN Community for being reference which will lead to benefit among nursing profession in ASEAN.

The purpose of this paper is provided policy recommendations to enhance nursing education and services among ten ASEAN country members. ASEAN countries are sources of nurses as well as hosts for foreign nurses. They also provide opportunities for host and foreign nurses to gain and share experience and knowledge to facilitate migration to other countries. In addition, the following part will provide you more about the background of nursing education and services from each respect member country, followed by the findings of the SWOT analysis health service sector conducted among ASEAN countries, followed by the barrier to develop nursing education and nursing service in ASEAN countries. Furthermore, it will provide clearly policy recommendations to strengthen nursing profession of AEC.

\section{Overview of health care sector in the ASEAN}

"Leaders take the first step to lead the leap of the organization. Make sure you'll all do." stated on 13th HA national forum in the topic 'Challenges of AEC for Healthcare Leaders, ${ }^{11}$ More recently, faculty of nursing, Chulalongkorn University organized international symposium in order to discuss the enhancement and strengthening nursing education and nursing services. This symposium was invited nurse leaders from respect ASEAN member countries to share their knowledge and experiences. This is the briefly characteristic about nursing academic system and nursing service system among ASEAN countries that summarizing in Table 1.

\section{The barrier to develop nursing education and nursing service in ASEAN countries}

There is a matrix issue, which ten ASEAN member countries have faced, where International Symposium produced fruitfully information (Table 2).

Furthermore, there are the barrier to develop nursing education and nursing service in ASEAN countries, which are language, the national licensure examination, nurse education, and nursing regulatory authority. ${ }^{5}$

\section{Language}

In Asian countries, language is the importance that needs to take in to consideration when discussing the movement of nurses. Language ability is important for nurses and their work for communicate with medical professionals to deliver quality health care without failure or misunderstanding. ${ }^{12}$ Another is the and expectations of patients towards nurses are much more than just being able to talk, but provide caring for them. It is linked with cultural values, which greatly affects their participation with patients. The fact that Filipino nurses who can speak English fluently tend to be placed in the departments 
where direct verbal interactions with patients are relatively limited. Moreover, sharing the common language is an advantage in facilitating the development of nurses. In Asian countries only among countries
Singapore, India, and Malaysia, which used English as an official language or as a widely spoken language? Language requirements definitely deter foreign nurses to work abroad. ${ }^{13}$

Table 1: Characteristic about nursing academic system and nursing service system among ASEAN countries.

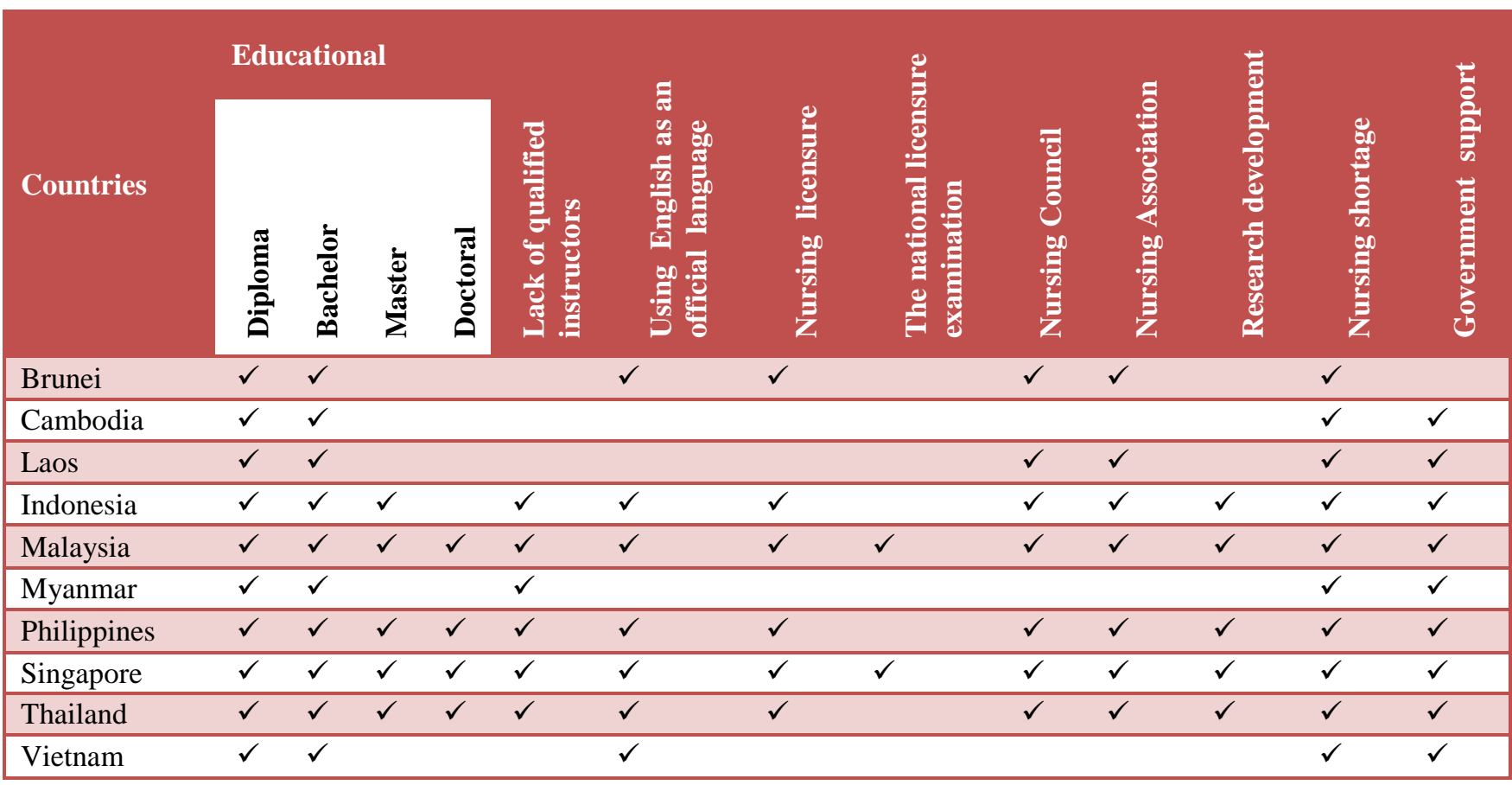

\section{The national licensure examination}

In connection to the language requirements, most of Asian countries conduct National Licensure examinations in the National Language only. Only Singapore and Malaysia introduced a separate examination for foreign and/ or foreign-trained nurses. The Singapore Nursing Board conducts the licensure examinations for foreign nurses in English. ${ }^{7}$ In 2005 the Board conducted 12 such examinations not only in Singapore ${ }^{14}$, but also in the Philippines, China and India. This arrangement has facilitated a smooth movement of nurses to Singapore. In Malaysia, the Nursing Board Malaysia provides the Temporary Practice Certificate (TPC) to foreign nurses to foreign nurses from seven countries who meet the requirements set by the Board. ${ }^{15}$ This system facilitates the outflow of nurse migration from Malaysia to other countries as student's can study nursing in English and receive national nursing license in English. In most case, nurses who study nursing in English still need to pass the national licensure examination in their national language. This adds the burden to nurses who receive nursing education in the English language in non-English speaking countries. Nurse education.
Asian countries have their own national training curriculum, which can be very different from that of major destination countries for nurses. For facilitate the nurses development, it is important to create the quality and contents of nursing education among countries, it may be challenge if the curricula and the concept of nursing are very difference in each countries. Moreover, the instructors who can train nurses are limited. Most countries in Asia require passing the national licensure examination their own national languages. Thus those who attend the English language program need to study nursing in two languages (Malaysia and the Philippines are the exceptions). ${ }^{15,16}$ Nursing Regulatory Authority

It is important to have established Nursing Regulatory Authorities in each country that supervise the registration of nurses and the quality of nurse qualifications to uphold professional nursing standards. There difference in capacity nursing regulatory authority in each countries, some countries still do not have strong and established nursing regulatory authority. It may be insufficient to establish in Cambodia, ${ }^{17,18}$ Indonesia, ${ }^{19}$ Lao, ${ }^{20,21}$ Viet Nam, ${ }^{22}$ Brunei Darussalam, ${ }^{23}$ and Myanmar. ${ }^{24}$ 
Table 2: Matrix issues from ASEAN member countries.

\begin{tabular}{|c|c|c|}
\hline Countries & Nursing education & Nursing services \\
\hline Brunei & $\begin{array}{l}\text { 1. Lack of qualified instructors } \\
\text { 2. Future need: Master and PhD prepared } \\
\text { nursing instructors } \\
\text { 3. No curriculum Master and Doctoral degree } \\
\text { in Nursing \& midwifery } \\
\text { 4. Lack of academic staff, there are no } \\
\text { Associate Professors or professors of } \\
\text { Nursing or Midwifery employed }\end{array}$ & $\begin{array}{l}\text { 1. Imbalanced of graduates } \\
\text { produced to meet the } \\
\text { demands of the workforce in } \\
\text { the Ministry of health. }\end{array}$ \\
\hline Cambodia & $\begin{array}{l}\text { 1. Shortage numbers of faculty } \\
\text { 2. Low educational faculty } \\
\text { 3. Medical doctor is dominant in nursing } \\
\text { education } \\
\text { 4. Lack of regulations, guideline, and law to } \\
\text { support nursing education }\end{array}$ & 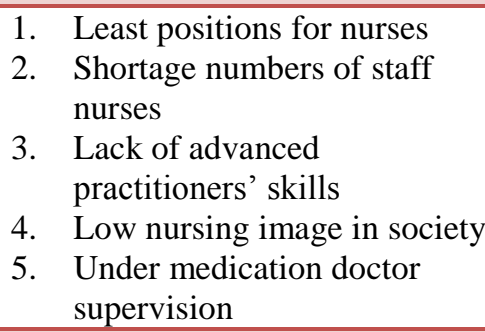 \\
\hline Laos & $\begin{array}{l}\text { 1. Low degree of nursing educational faculty } \\
\text { 2. Shortages numbers of faculty } \\
\text { 3. Lack of skills and funds to support research } \\
\text { 4. Lack of infrastructure for teaching and } \\
\text { 5. Lack of teaching-learning skills' faculty }\end{array}$ & No license system yet \\
\hline Indonesia & $\begin{array}{l}\text { 1. Lack of teaching-learning faculty's } \\
\text { knowledge } \\
\text { 2. Lack of advanced specialty skills for faculty } \\
\text { 3. Lack of funds to support for nursing } \\
\text { professional development }\end{array}$ & $\begin{array}{l}\text { 4. Shortages numbers of nurses } \\
\text { 5. Low incoming employee } \\
\text { 6. Culture diversity } \\
\text { 7. Lack of human and financial } \\
\text { resources for conducting } \\
\text { research }\end{array}$ \\
\hline Malaysia & $\begin{array}{l}\text { 1. Low enrollment new students } \\
\text { 2. Shortages numbers of faculty }\end{array}$ & \\
\hline Myanmar & $\begin{array}{l}\text { 1. Lack of higher educational nurse to } \mathrm{PhD} \\
\text { 2. Lack of teaching materials } \\
\text { 3. Shortage numbers of faculty } \\
\text { 4. Lack of financial support sending faculty to } \\
\text { study higher levels }\end{array}$ & $\begin{array}{l}\text { 1. Shortages numbers of staff } \\
\text { nurses } \\
\text { 2. Lack of standard of } \\
\text { professional practice } \\
\text { 3. Different curriculum } \\
\text { 4. Different scope of practice } \\
\text { 5. Culture diversity }\end{array}$ \\
\hline Philippines & $\begin{array}{l}\text { 1. Lack of numbers of faculty who does not } \\
\text { meet qualified requirement } \\
\text { 2. Decline passing rates of national exam } \\
\text { 3. Low enrollment of new nursing students } \\
\text { 4. Concern in equivalency of curriculum }\end{array}$ & 1. Shortages numbers of nurses \\
\hline Singapore & & $\begin{array}{l}\text { 1. Growing of aged people } \\
\text { 2. Raising costs for health care }\end{array}$ \\
\hline Thailand & No specific issue & No specific issue \\
\hline Vietnam & $\begin{array}{l}\text { 1. No standardized nursing procedures } \\
\text { 2. Lack of qualified faculty } \\
\text { 3. Lack of PhD prepared faculty } \\
\text { 4. Shortages numbers of faculty } \\
\text { 5. Lack of teaching-learning references }\end{array}$ & $\begin{array}{l}\text { 1. Low nurse image } \\
\text { 2. Shortages numbers of nurses } \\
\text { 3. Medical dominates to nurses } \\
\text { 4. Lack of autonomy } \\
\text { 5. Lack of clinical skills }\end{array}$ \\
\hline
\end{tabular}




\section{Recommendation}

Health care profession especially nurse for AEC in 2015 should be based on existing differences in the regulatory frameworks governing the health sectors in various ASEAN countries. Health and medical sector is a highly regulated sector in many countries since it is considered a basic right sometimes enshrined the fundamental law of the country. Because of this, many citizens and to some extent policy makers in the several countries view health as a non-tradable service that should not be subjected to global market forces. ${ }^{25,26}$ But because of limited public funds for medical and health services, on the one hand, and the increasing demand for efficient health care systems in many countries, on the other hand, trade in health services becomes very crucial in offering access to better quality of health care.

However, because of the differences in domestic regulation there is a need to standardize these regulatory frameworks to allow the greater trade in services within the region. In particular, there is a need to liberalize the limitations on market access, national treatment and domestic regulation to make the health sector market friendly to domestic and foreign consumers and suppliers within the region.

According to the conference, we will propose the guideline for enhancing nursing education and nursing service in ASEAN countries as:

\section{Nursing education:}

1. ASEAN countries need to strengthen their collaboration on a network basis in nursing education so that the stocks and flows of nursing practitioners would be able to maximize the opportunities provided in ASEAN liberalization of nursing services while proactively contributing to healthy ASEAN population and ASEAN Community.

2. Improve the quality of education to meet the skill and development needs of the workforce in changing service environment.

3. Increased political, technical and financial support for leadership capacity building, implementation and monitoring of nursing/midwifery regional and national development plans by regional and sub-regional networks.

4. Leadership for change programmers instituted, monitored and evaluated, nationally and subregionally, through collaborative partnerships by networked communication established among program graduates, between countries to support continued process of change/ improvement.

5. Increased capacity to analyze, develop, update implement and monitor and sustain/ strengthen legislative systems and process, including regulatory councils/boards.
6. The policy making should to reduce costs to study in nursing program for available students to entrance to nursing profession. National advertising, recruitment and incentive campaigns may be help to increasing enrolments in nursing schools in some countries.

Nursing service:

1. ASEAN countries need to develop motivated and competent nursing manpower/workforce with appropriate distribution and workload, Support the provision of quality patient care, Improve the motivation, productivity and performance of individuals and organization, Ensure the health, safety and personal wellbeing of staff.

2. Involve employees in planning and decision making, Provide clear and comprehensive job descriptions/specifications, Encourage open communication, collegiality, team work and supportive relationships, Encourage the reporting of professional misconduct or violation of laws/regulations.

3. Foster strong employment relationships: employer/employee/coworkers/patients engage employees in assessment and improvement of work design and organization promote healthy work-life balance by manageable workloads and flexible work arrangements, regularly review scope of practice and competencies.

4. Policy designed to reduce flows of nurses out of the workforce appear to relatively under developed in ASEAN countries, as a first step, countries need to make more efforts to maximize participation of qualified nurses in the workforce by introducing family, friendly policies, in the context of an ageing nurses workforce, incentives for nurses to retire early need to be replaced by policies that aim to reduce the rate at which nurses take early retirement, delay retirement of nurse and attract retired nurses back into the workforce.

5. Policy needs to focus on introducing workplace strategies that retain nurses such as the Magnet Nursing Services Recognition Program in the United States. Evidence is also emerging that nurse retention can be enhanced by employing fewer nurses.

\section{CONCLUSIONS}

The International Symposium, which was held by Chulalongkorn University, is key instrument to brainstorm some important issues as shortage numbers of nurses, low educational nurses to perform with complex tasks, and culture barriers. For nursing education, the ten ASEAN member countries must strengthen network, to improve quality of nursing education, and improve enrollment in nursing school. Additionally, nursing 
services have to be improved nursing work environment, to work collegiality, and mange strategic plan effectively. This policy recommendation will give ASEAN nurse leaders get important information for future improvement in terms of collaboration among ten member countries.

Funding: No funding sources

Conflict of interest: None declared

Ethical approval: Not required

\section{REFERENCES}

1. Tullao T. \& Cortez, M. Enhancing the movement of natural persons in the ASEAN region: Opportunities and Constrains. (2006).

2. Heller BR, Oros MT, Durney-Crowley J. The future of nursing education, 10 trends to watch. Nursing Health Care Perspective 2000;21(1):9-13

3. Association of Southeast Asian Nations. ASEAN Economic Community Blueprint. Jakarta: 2008; ASEAN Secretariat.

4. World Health Organization and Department of Health. (2014). Singapore Health Service Delivery Profile.

5. Cirujales RM, Kuan L. Nurse Migration, Deployment, Enrollment and Board Passing Trends in the Philippines (1999-2008), Philippine Journal of Nursing 2000, 82(1).

6. Mutual Recognition Arrangement. ASEAN Joint Coordinating Committee in Nursing 2008.

7. Sidorenko A, Manning C. The regulation of professional migration in the ASEAN. Insights from the health and IT sectors. The Australian National University 2005.

8. Thomas S, Billington A, Getliffe K. Improving continence services: a case study in policy influence. Journal of Nursing Management 2004; $12: 252-7$.

9. Cohen SS, Milone-Nuzzo P. Advancing Health Policy in Nursing Education through Service Learning. Article 2001;3:28-40.

10. International Council of Nurses. Participation of Nurses in Health Services Decision Making and Policy Development. (2010).

11. Kunaviktikul W. Nursing and nursing education in Thailand: The past, the present, and the future. Nursing and Health Sciences. 2006;8:199-200.

12. Chang M, Feller M, Nimmagadda J. Barriers to Healthcare Access in the Southeast Asian
Community of Rhode Island. Medicine \& Health/Rhode Island 2009;92(9):310-3.

13. Seminar. Two Years on Our Way: How Ready is ASEAN for Integration in 2015. Held at the CME Auditorium, University of Santo Tomas, Espana, Manila.

14. Singapore Board of Nursing. http://www.healthprofessionals.gov.sg/content/hprof /snb/en/ topnav/home.html

15. Malaysian Board of Nursing. http://nursing.moh.gov.my/.

16. Philippines Nursing Board. http://www.prc.gov.ph.

17. Cambodian Council of Nurses. https://sites.google.com/site/cambodianccn/.

18. Hong R, Betancourt J. Healthcare in Cambodia. The provision of health care in Cambodia at a glance. Retrieved September 2006. Economic Institute of Cambodia. http://www.eicambodia.org/downloads/files/provisi on.pdf

19. Ministry of Health of Indonesia. http://www.observatorisdmkindonesia.org

20. Ministry of Health of Lao PD. (2006). Law on health care. Vientiane Capital: $\mathrm{MOH}$.

21. Ministry of Health of Lao PD. (2007). Executive Summary of Sixth Five-Year Health Sector Development Plan. Vientiane Capital: MOH.

22. Ministry of Health of Vietnam. (2013). National Programmed of Action for Strengthening Nursing and Midwifery Services from now to 2020. Decision 1215/QD-BYT.

23. Ministry of Health of Brunei Darussalam. (2011). Health Information Booklet. Retrieved, 2014, from www.moh.gov.bn.

24. National Health Plan. (2011-2013). Myanmar.

25. Urata, S. (2009). A Shift from Market-Driven to Institution-Driven Regionalization in East Asia. Waseda University Summer Seminar, Creating Cooperation and Integration in Asia. Graduate School of Asia-Pacific Studies, Waseda University. (Unpublished Monograph).

26. Arunanondchai J, Fink C. Trade in Health Services in the ASEAN Region. December 2010.

Cite this article as: Koy V. Policy recommendations to enhance nursing education and services among Asean member countries. Int J Adv Med 2015;2:324-9. 